\title{
Optimal Reservoir Sizing for Small Scale Water Harvesting System at Al-Hader in Northren Iraq
}

\author{
Dr. Ahmed Y. Hachum \\ Dr. Mohammad E. Mohammad \\ Professor \\ Lecturer \\ Water Resources Engineering Department, College of Engineering, \\ University of Mosul, Mosul, Iraq
}

\begin{abstract}
A procedure is presented for determining the optimum reservoir size for supplemental irrigation using Linear Programming technique. The volume of water stored depends on the available runoff during the time interval considered along the rainy season, and the water demand which also varies depending on stage of plant growth. The runoff amount is estimated using the well-known Soil Conservation Services (SCS) curve number method. The required input data for the model are the daily rainfall depth for each time interval, soil type, construction cost per unit volume of reservoir, loss of economical return per unit area of land left as a catchment, and the maximum allowable catchment area which depends on total available area of land considered. The computerized model consists of two parts; in the first part, the program formulates the input data in the form of Linear Programming problem, while in the second part the program solves the problem by the Simplex method. The model is applied using data for Al-Hader area in Nineva Governorate. The long-term mean annual rainfall of the selected site is about $150 \mathrm{~mm}$. The results showed that the most economic design is the one in which the required harvesting area is about three quarters of the total area under consideration. In this case the yield is sub-maximal, but most economical, and the irrigation depth is only about $87.5 \%$ of the case that gives the maximum yield. The required reservoir volume for the most economic design is about $111 \mathrm{~m}^{3} / \mathrm{ha}$ of the land area considered.
\end{abstract}

Keywords: linear programming, modeling and simulation, reservoir sizing, supplemental irrigation, water harvesting.

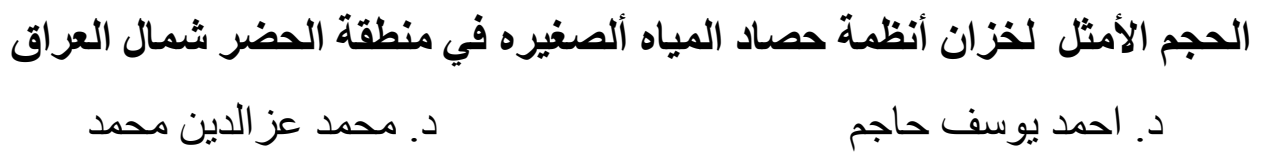




\section{استاذ مدرس \\ قسم هنسة الموارد المائيه، كلية الهندسه، جامعة الموصل، الموصل ـ العرق}

\section{الخلاصه}

تم تقديم نموذج محاكاة لإيجاد الحجم الأمنل للخزان اللازم لاغر اض الإنه الري التكميلي

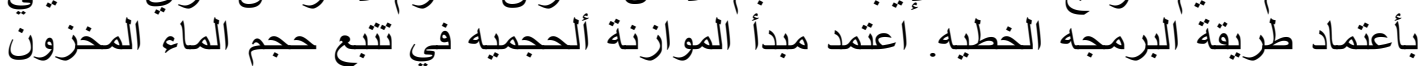

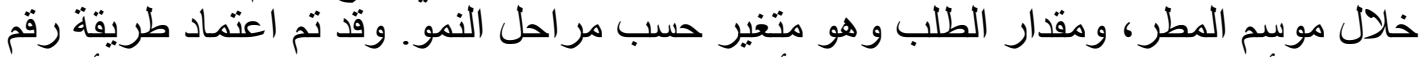

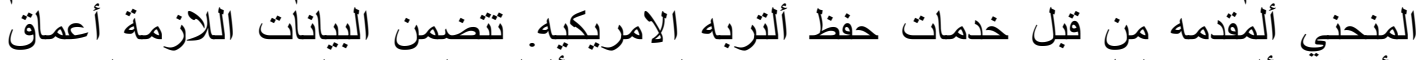

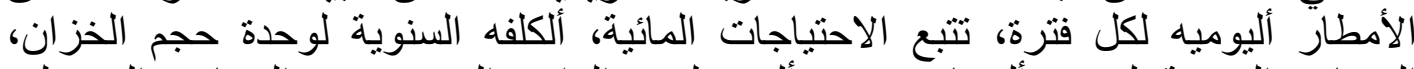

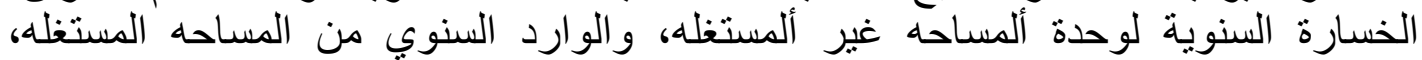

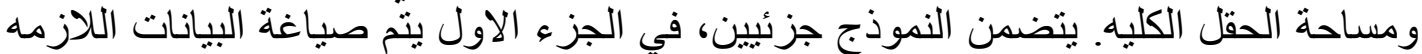

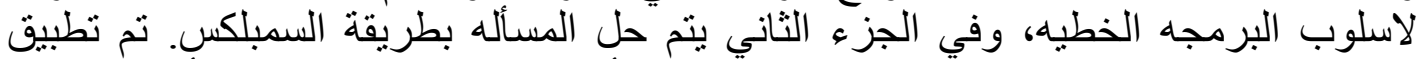

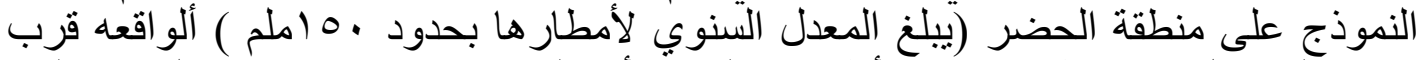

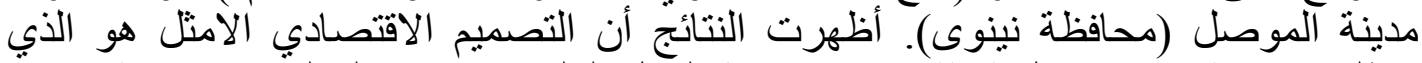

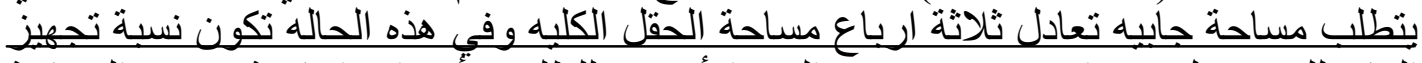
الماء

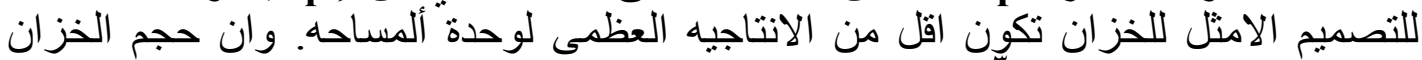

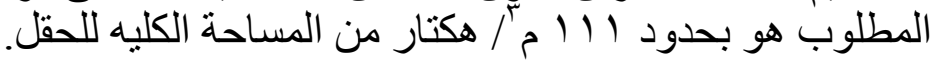




\section{Introduction}

Most areas with low rainfall suffer from low and unstable crop yield. In these low rainfall areas, the water use efficiency is extremely low since most of the rainwater is lost by soil surface evaporation and/or runoff to salt sinks. Therefore, the productivity of the land and water are both low. By intervening, via water harvesting, the productivity of the rainwater can be significantly improved, through concentrating the rainwater on part of the land. Often, one life- saving irrigation to rainfed crops at the most critical growth stage could substantially improves yield.

Water harvesting can be defined as the process of collecting runoff water and storing it for future beneficial use, [1,2]. This use may includes domestic (drinking and other home uses), irrigation (crop use), and even industry. Generally, storage of rainfall in the soil profile for crop use is cheaper and more efficient than storage of runoff in excavated tanks. However, the major limitation of storage in the soil profile is its limited capacity. In most of the rainfed areas, rain-water conservation measures cannot conserve all the rain- water and a certain amount of runoff is bound to occur. This runoff can be harvested (collected and stored) in tanks for a life-saving irrigation to rainfed crops.

Use of water harvesting tanks in rainfed areas has come into vogue only recently. A simulation model combining a watershed runoff model and a corn grain model to determine the reservoir site necessary to ensure the availability of water on a probability basis of irrigation was developed, [3]. Return period calculations are made on yields to obtain probability curves of yield as a function of reservoir size for the simulation period. This information enables users to make better decision regarding selection and design of irrigation water supply reservoirs.

A procedure for determining the optimal reservoir size, based on economics, for supplemental irrigation was presented, [4]. The procedure can also be used to evaluate the risk involved in investing supplemental irrigation.

A model of rainfall-runoff response from spatially varied storage dominated watershed was developed, [5]. The framework of the model is 
flexible in that it has previously been used to describe rate controlled watershed.

A procedure to design a tank for water harvesting and compute its benefit-cost ratio for a region in northern Punjab was developed, [6]. It was observed that the total cost of tank per unit of capacity decreased with increasing tank capacity. The results show that tanks designed on the basis of seasonal runoff and used for pre-sowing irrigation of wheat, are the most beneficial with a benefit-cost ratio ranging from 1.6 to 4.5 for catchment are varying from 1 to 100 ha. The probability level of the lowest assumed runoff corresponding to the lowest annual cost per unit of available water increased with increasing tank capacity and varied from 40 to $80 \%$.

A desktop method to analyze or size detention ponds and outlet facilities was presented, [7]. Different initial conditions are allowed when used for design purposes. The method determines the size of the outlet facility for a given pond. However, if the pond is inadequate to meet the design criteria set, the method determines the required storage stage relationship. The method is based on the usual reservoir-routing technique that couples the hydrologic-storage equation with an expression describing the flow through the outlet structure. A computer model is used to solve the governing equations using a finite difference scheme. The numerical results obtained in terms of systematically chosen combinations of the governing dimensionless parameters are generalized based on the concept of similarity.

A simple simulation model containing few parameters for a water harvesting strip farming system was described, [8] . The model includes runoff - threshold functions for different soil types and for different initial soil water contents. The evapotranspiration component of the model accounts for dynamic root water extraction using regression equations. The model is simple to operate and uses readily available inputs. It can work with several crops when leaf area indices and crop stage coefficients are provided. The agreement between simulation outputs and field observed data indicates that the model accurately describes the water balance within the system. The model is recommended for obtaining preliminary design of water harvesting systems. 
The small water harvesting reservoirs are a viable option in the dry areas, [9]. If properly planned, designed and implemented, they improve rainwater use efficiency, agricultural development, and environment. However, unless selection is based on maximizing water use efficiency, they might not be the best option. Making water available for agriculture may not necessarily mean good agriculture. Several problems both technical and socioeconomic need to be solved before water use efficiency is maximized. In the mid eighties, they initiated a research site in a typical area of the Jordan Badia (Muaqqar) to investigate the potential use and improved management options of small farm reservoirs and followed up on it since then. Three small earth dams were built across a wadi creating farm reservoirs. The reservoirs are used to irrigate research plots of field crops and trees at the Jordan University Station. The experiences gained from this work are immense.

A model to predict the optimum size of the on-farm reservoir so as to provide supplemental irrigation to rice in monsoon season, pre-sowing irrigation to mustard in winter and to support fish cultivation in rainfed farming systems in Eastern India was developed, [10]. The model is based on water balance approach for both the crop field and the reservoir, where hydro-meteorological parameters and the irrigation management practices are input to the model.

The objective of this paper is to develop a simulation model for water harvesting and to find the optimal size of the reservoir of the system that maximize the net economical return.

\section{The Simulation Model}

A mathematical computerized model based on Linear Programming technique has been presented here to optimize the size of a storage tank or reservoir for supplemental irrigation depending on runoff volume. It is assumed that all the runoff coming from the catchment area enters the reservoir. Figure (1) shows the basic parameters considered in the model. 
The model described here analyzes the relationship between moisture added to the soil, through precipitation and runoff that is required for crop growth. The daily rainfall data available for the record years are used in estimating the value of runoff volume for rainy days. Daily runoff occurs when the daily rainfall exceeds threshold depth value

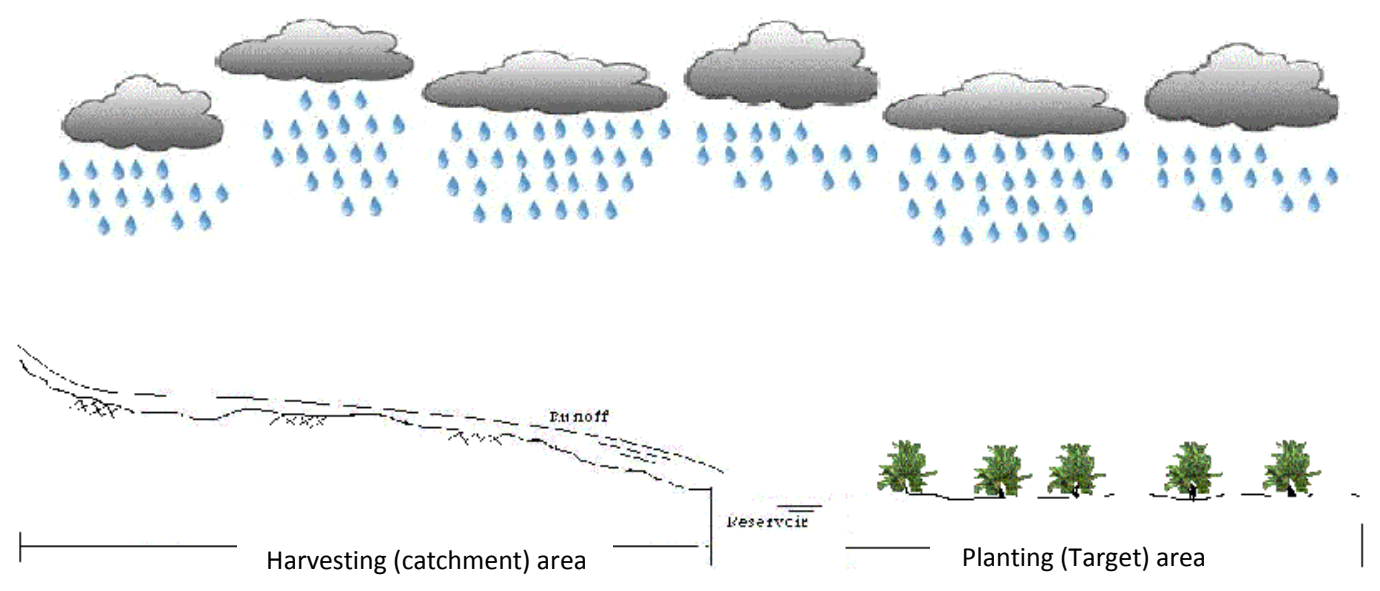

which in turn depends on the characteristics of the catchment area, mainly slopes and surface conditions.

\section{Figure(1):Conceptual and basic parameters of the proposed} simulation model.

The decision input for water harvesting is runoff water that can be harvested in the site. To calculate the runoff amount, the Soil Conservation Services (SCS), Curve Number (CN) methodis chosen, [11]. It calculates the runoff $\left(R_{o i}\right)$ in millimeters induced by daily rainfall through the following equations:

$$
R_{o i}=\frac{\left(R_{i}-0.2 S\right)^{2}}{R+0.8 S} \quad \text { if } R>0.2 S
$$




$$
R_{o i}=0 \quad \text { if } R \leq 0.2 S
$$

Where:

$$
\begin{aligned}
& R_{o i}=\text { Daily runoff amount in millimeters, } \\
& R_{i}=\text { Daily rainfall amount in millimeters, and } \\
& S=\text { Storage or retention of the soil in millimeters. }
\end{aligned}
$$

If rainfall is small $\left(R_{i} \leq 0.2 S\right)$, all water goes into the storage of the soil and no runoff takes place. If rainfall is high enough $\left(R_{i}>0.2 S\right)$, runoff takes place according to equation (1a). The curve number $(C N)$ simplifies all these influences into one parameter and determines $(S)$ by the following equation:

$$
S=25.4 *\left[\frac{1000}{C N}-10\right]
$$

in which:

$S \quad=$ Storage or retention of the soil in millimeters, and $C N=$ Curve number.

The total daily runoff volume can be then computed using the following equation:

$$
V_{i}=R_{o i} * A
$$

where:

$$
V=\text { Volume of runoff water for } \mathrm{i}^{\text {th }} \text { day, and }
$$


$A=$ Catchment area

In areas where surface water must be stored for later uses in irrigation and other purposes, a system for determining a reservoir water balance and reservoir's size must be employed. The proper sizing of this reservoir must start by considering all inflows to and outflows from it.

The inflow to the reservoir is equal to the runoff volume:

$I_{i}=V_{i}$

where:

$I_{i}=$ Volume of inflow water to the reservoir for the $\mathrm{i}^{\text {th }}$ day. and

$V_{i}=$ Volume of the runoff volume of $\mathrm{i}^{\text {th }}$ day.

The outflow from the reservoir includes (a) the irrigation demand that depends on the actual evapotranpiration EVP, (b) the evaporation from water surface area of the reservoir and (c) surplus water (spill).

Supplemental irrigation is assumed to take place whenever, the soil water depletion reaches a level close to a predefined depletion level, which is usually taken at $50 \%$ depletion of the total available water in the root zone of the crop.

In order to determine the reservoir size, an initial storage $\left(S_{O}\right)$ is assumed. The outflow $\left(O_{i}\right)$ from the reservoir is equal to the demand rate of irrigation, evaporation loss from reservoir water surface area, and spilled water. The seepage losses from the reservoir is assumed zero because of lining the bottom and reservoir sides with plastic material. For the purpose of model formulation, the area of the water surface and the total wetted surface area of the reservoir are expressed as functions of the antecedent water storage, and reservoir volume, respectively. Therefore, a certain shape for the reservoir is assumed. The reservoir shape 
considered in this study is inverted truncated pyramid with a square base, and a side slope if $1 \mathrm{~V}: 1.5 \mathrm{H}$.

The objective function is to maximize the total return by considering the benefit per unit mass of yield per unit of planting area, losses for not cropping (harvesting) area under rainfed conditions, and reservoir cost per unit volume. The total cost of a reservoir includes its construction, lining cost and cost of inlet and spillway structure, therefore the objective function in terms of benefits will have the following form:

Maximize total benefit $C_{T B}=Y \cdot C_{y} \cdot A_{r}-C_{a} \cdot A_{c}-C_{r} \cdot V_{r}$

in which:

$C_{T B}=$ Net yearly benefit,

$Y=$ Yield per unit area,

$C_{y}=$ Return per unit mass of yield,

$A_{r}=$ Cropped area (Target),

$C_{a}=$ Cost per unit harvesting area, reflects yearly loss of rainfed production per unit area of catchment,

$A_{c}=$ Catchment area,

$C_{r}=$ Cost per unit volume of reservoir, includes its construction, lining cost and cost of inlet and spillway structure.

$V_{r}=$ Volume of reservoir.

This function is subject to a number of constraints that must be considered. The first constraint in the reservoir routing (volume balance in cubic meter) equation, for five-day intervals which can be expressed as follows: 


$$
S_{j}+I_{j}-O_{j}=S_{j+1}
$$

in which:

$S_{j}=$ Storage volume at the beginning of time interval $(j)$

$I_{j}=$ Inflow volume to the reservoir during the time interval $(j)$

$O_{j}=$ Outflow volume (supplemental irrigation water volume plus evaporation loss from reservoir, and spill water through the time interval, $j$ )

$S_{j+1}=$ Storage volume at the end of time interval $(j)$ which is the same at the beginning of time interval $(j+1)$.

and

$$
S_{j} \leq V
$$$$
j=
$$$$
1,2,3, \ldots
$$$$
n
$$

in which:

$$
\begin{aligned}
& V=\text { reservoir volume, and } \\
& n=\text { number of time intervals. }
\end{aligned}
$$

The outflow volume $O_{j}$ at the time interval $j$ can be expressed by the following form:

$$
O_{j}=D R_{j}+E V_{j}+S P_{j}
$$

In which; 
$D R_{j}=$ volume of demand rate at time interval $j ;$

$E V_{j}=$ volume of evaporation loss from the reservoir; and

$S P_{j}=$ spilled water volume through time interval $j$.

The evaporation loss during each time interval is estimated based on available data of Class-A pan evaporation of and water surface area of the reservoir, $R S a\left(\mathrm{~m}^{2}\right)$, which can be estimated by the following relation:

$$
R S a=X_{1} \cdot S_{i}+X_{2}
$$

In which;

$X_{1}$ and $X_{2}$ are constants based on reservoir shape, side slopes, and base dimensions

Also the lining area, $L A\left(\mathrm{~m}^{2}\right)$, can be estimated based on reservoir volume, $\mathrm{V}\left(\mathrm{m}^{3}\right)$, by the following form:

$$
L A=X_{3} \cdot V+X_{4}
$$

In which; 
$X_{3}$ and $X_{4}$ are constants based on reservoir shape, side slopes, and base dimensions.

In this study, it is assumed that complete runoff resulting from the catchment area treated with an in-situ water conservation procedure, enters the reservoir, and suitable inlet and spillway structure are provided. The reservoir capacity for silt accumulation is considered which is equal to $\left(\mathrm{S}_{1}\right)$, the volume of dead storage or the minimum required volume at the beginning and end of rainfall seasonal. This volume is to provide a minimum required depth for pumping and operation of the system.

The constraint in Equation $6 \mathrm{~b}$ is applied for each time interval, therefore, the number of this constraint is equal to the number of time intervals considered. Another constraint regarding the limitation on the total area of land is also added to the set of constraints of equation (6). The land area constraint is in the following form:

$$
A_{c}+A_{r}=A_{f}
$$

$A_{c}=$ The catchment (harvesting) area,

$A_{r}=$ Irrigated area, and

$A_{f}=$ total area considered in the problem, given as a limited value.

\section{Model Application and Results}

The simulation model is run for different degree of water availability to crop by supplementing the rainwater to different levels 
varying from only rainfed to $100 \%$ crop water requirement. As the level of water availability to crop is increased, the catchment (harvesting) area increases while the cropped area decreases.

The model is applied for the Al-Hader area $\left(35^{\circ} 35^{\prime} 47^{\prime \prime} \mathrm{N}\right.$, $42^{\circ} 40^{\prime} 00^{\prime \prime}$ E), Nineva Governorate in northern Iraq. The location of the selected site, which is meant to be suitable for water harvesting implementation is shown in Figure (2). The soil of the study area is generally silty clay loam. Barley crop which is suitable for low rainfall areas is selected for model application. The growing season is six months long (November to April, therefore $\mathrm{n}=36$ in Equation 6b) with mean annual rainfall of $142 \mathrm{~mm}$. This quantity of mean annual rainfall is usually not enough to grow any economical crop.

A number of trial runs are conducted in which the evaporation losses from the reservoir and lining cost are neglected. The results of these trial runs indicated that the required reservoir volume is about $950 \mathrm{~m}^{3} / 10$ ha of land area. Based on this result, suitable dam reservoir dimensions with a square reservoir base of $12.5 \mathrm{~m} * 12.5 \mathrm{~m}$, and side slope of $1 \mathrm{~V}: 1.5 \mathrm{H}$ are selected. Depending on these dimensions, the values of the constants $\left(X_{1}, X_{2}, X_{3}\right.$ and $\left.X_{4}\right)$ of equations (8), and (9) are 0.3132, $176.987,0.376$, and 181.173 respectively.

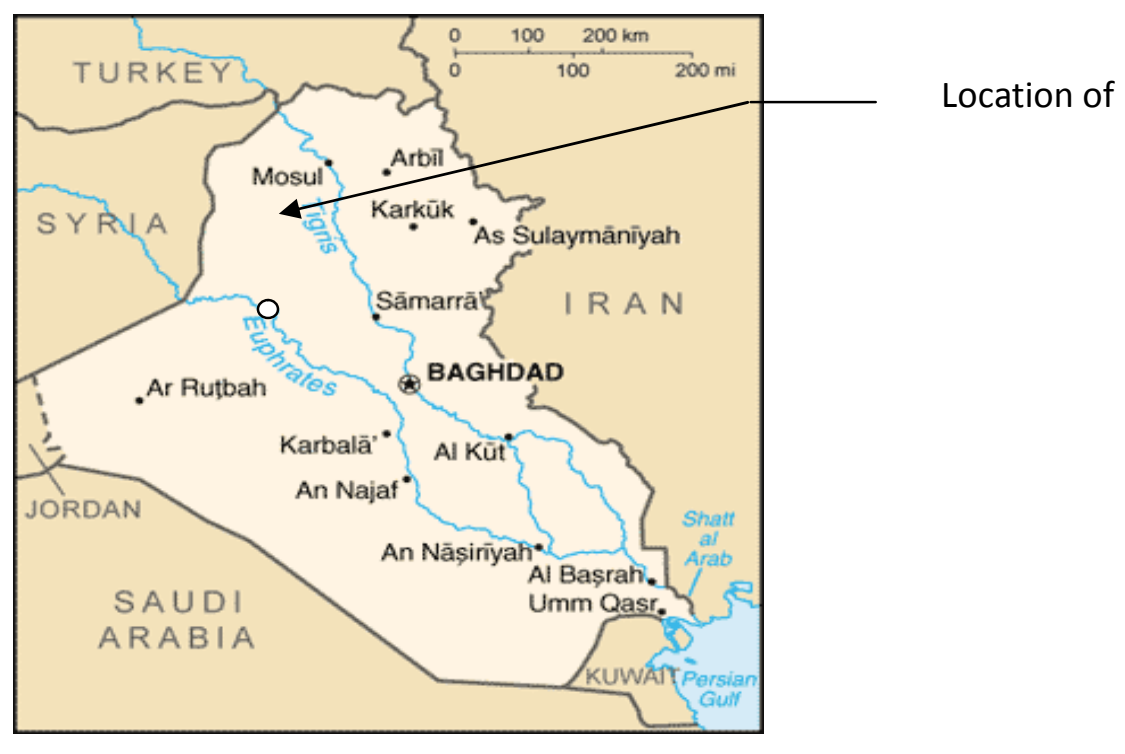


Figure (2): The location of the study area at Al-Hader, Nineva Governorate, Iraq.

The input data required to formulate the model is the rainfall data, evapotranspiration, cost (loss of rainfed production) per unit catchment area, cost per unit volume of reservoir, sale price per unit mass of yield, and total field area. The current market prices in the study area are adopted in the model application. In this study, the field area is taken as 10 ha of land. An average year (close to the long term mean rainfall year) is used in the application of the model. Table (1) presents data used in the linear programming formulation.

The results showed that the most important factors that determine the required harvesting area and reservoir size are the unit cost of catchment area and unit cost of reservoir volume. For the maximum demand rate (100\% crop water requirement satisfaction), the results showed that the required harvesting area is about $80 \%$ of the total catchment area and the required reservoir volume is about $1175 \mathrm{~m}^{3} / 10$ 
(ha). These results mean that the ratio of the harvesting area to the cropped area is around 4.0 , (i.e. $80 \%$ divided by $20 \%$ ). The demand rate is gradually decreased to about $62.5 \%$ of crop water requirement to study its effect on harvesting area, cropping area, reservoir volume, and the objective function value. As a result, Figure (3) shows the variation of relative net benefit due to decreasing of demand rate. The variation of the ratio of catchment area to cropped area due to variation of demand rate is also studied. Figure (4) shows this ratio against different levels of demand rate. The optimal benefit is obtained for the demand rate of $87.5 \%$ satisfaction of the maximal value of demand rate (which is usually called the crop water requirement). The harvesting area is about $75 \%$ of total area, This means that the optimal ratio of harvesting area to planting area is about 3 , and the reservoir volume is about $1110 \mathrm{~m}^{3} / 10$ ha of the total land area under consideration.

Table (1): The input data (1982-1992) for Al-Hader (Nineva Governorate) area as a case study for the simulation model.

\begin{tabular}{|c|c|c|c|}
\hline $\begin{array}{c}\text { Time from } \\
\text { planting date } \\
\text { ( Days ) }\end{array}$ & $\begin{array}{c}\mathbf{E t}_{\mathbf{~}} \\
(\mathbf{m m} / \mathbf{d a y} \\
\text { ) }\end{array}$ & $\begin{array}{c}\mathbf{E t}_{\mathbf{c}} \\
(\mathbf{m m} / \mathbf{d a y})\end{array}$ & $\begin{array}{c}\text { 5-day total rainfall at 50\% } \\
\text { probability } \\
(\mathbf{~ m m})\end{array}$ \\
\hline 5 & 1.47 & 0.41 & 9.9 \\
\hline 10 & 1.47 & 0.41 & 15.8 \\
\hline 15 & 1.47 & 0.41 & 6.6 \\
\hline 20 & 1.47 & 0.41 & 5.3 \\
\hline 25 & 1.47 & 0.45 & 3.0 \\
\hline 30 & 1.47 & 0.61 & 13.5 \\
\hline 35 & 0.7 & 0.37 & 12.3 \\
\hline 40 & 0.7 & 0.45 & 8.5 \\
\hline 45 & 0.7 & 0.53 & 3.6 \\
\hline 50 & 0.7 & 0.61 & 7.6 \\
\hline 55 & 0.7 & 0.69 & 14.5 \\
\hline 60 & 0.7 & 0.77 & 6.0 \\
\hline 65 & 0.79 & 1.1 & 13.4 \\
\hline 70 & 0.79 & 0.91 & 3.2 \\
\hline
\end{tabular}




\begin{tabular}{|c|c|c|c|}
\hline 75 & 0.79 & 0.91 & 11.7 \\
\hline 80 & 0.79 & 0.91 & 10.0 \\
\hline 85 & 0.79 & 0.91 & 8.8 \\
\hline 90 & 0.79 & 0.91 & 5.5 \\
\hline 95 & 1.17 & 1.35 & 13.4 \\
\hline 100 & 1.17 & 1.35 & 8.8 \\
\hline 105 & 1.17 & 1.35 & 9.4 \\
\hline 110 & 1.17 & 1.35 & 12.9 \\
\hline 115 & 1.17 & 1.35 & 11.7 \\
\hline 120 & 1.17 & 1.35 & 5.6 \\
\hline 125 & 2.15 & 2.43 & 13.9 \\
\hline 130 & 2.15 & 2.43 & 11.8 \\
\hline 135 & 2.15 & 2.43 & 16.5 \\
\hline 140 & 2.15 & 2.34 & 9.0 \\
\hline 145 & 2.15 & 2.34 & 21.8 \\
\hline 150 & 2.15 & 2.34 & 4.9 \\
\hline 155 & 3.33 & 2.63 & 4.1 \\
\hline 160 & 3.33 & 2.30 & 3.7 \\
\hline 165 & 3.33 & 1.96 & 4.5 \\
\hline 170 & 3.33 & 1.63 & 3.5 \\
\hline 175 & 3.33 & 1.29 & 6.3 \\
\hline 180 & 3.33 & 0.96 & 3.5 \\
\hline & & & \\
\hline
\end{tabular}

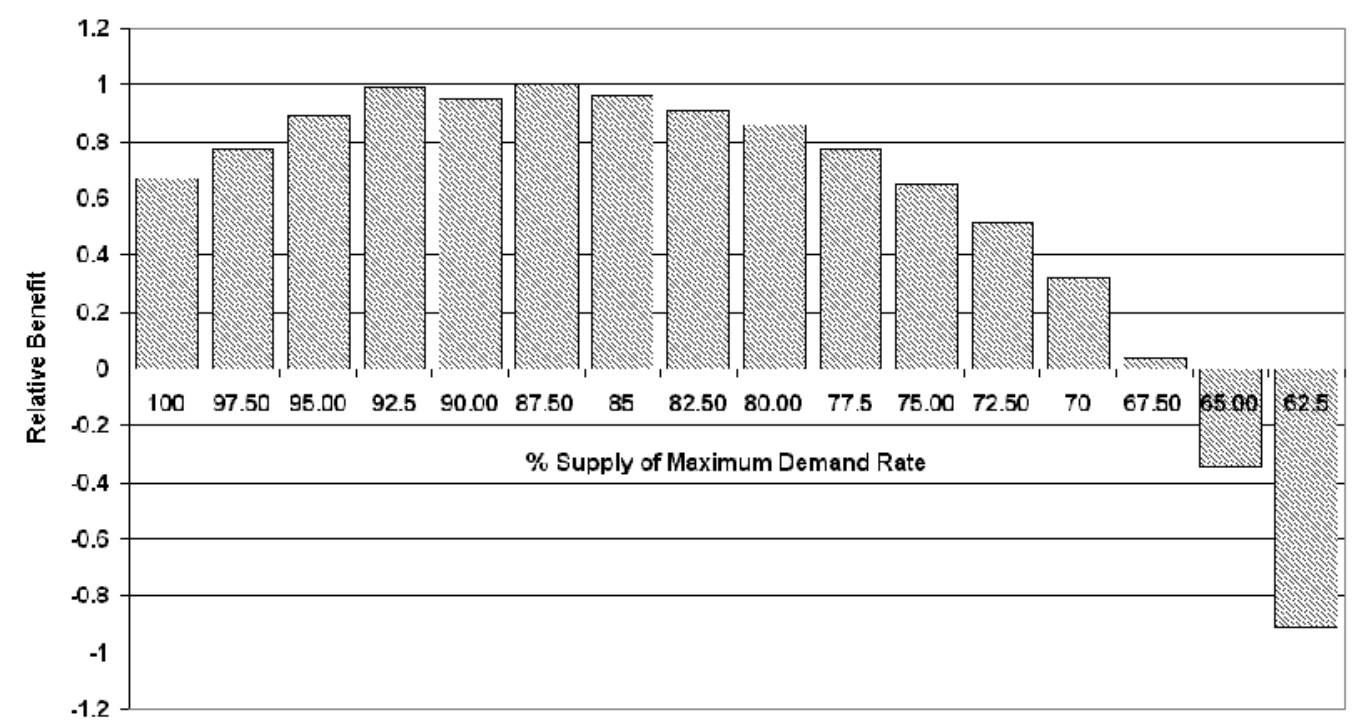

Figure (3): Variation of relative net benefit with decreasing percentage of supply of maximum demand rate. 


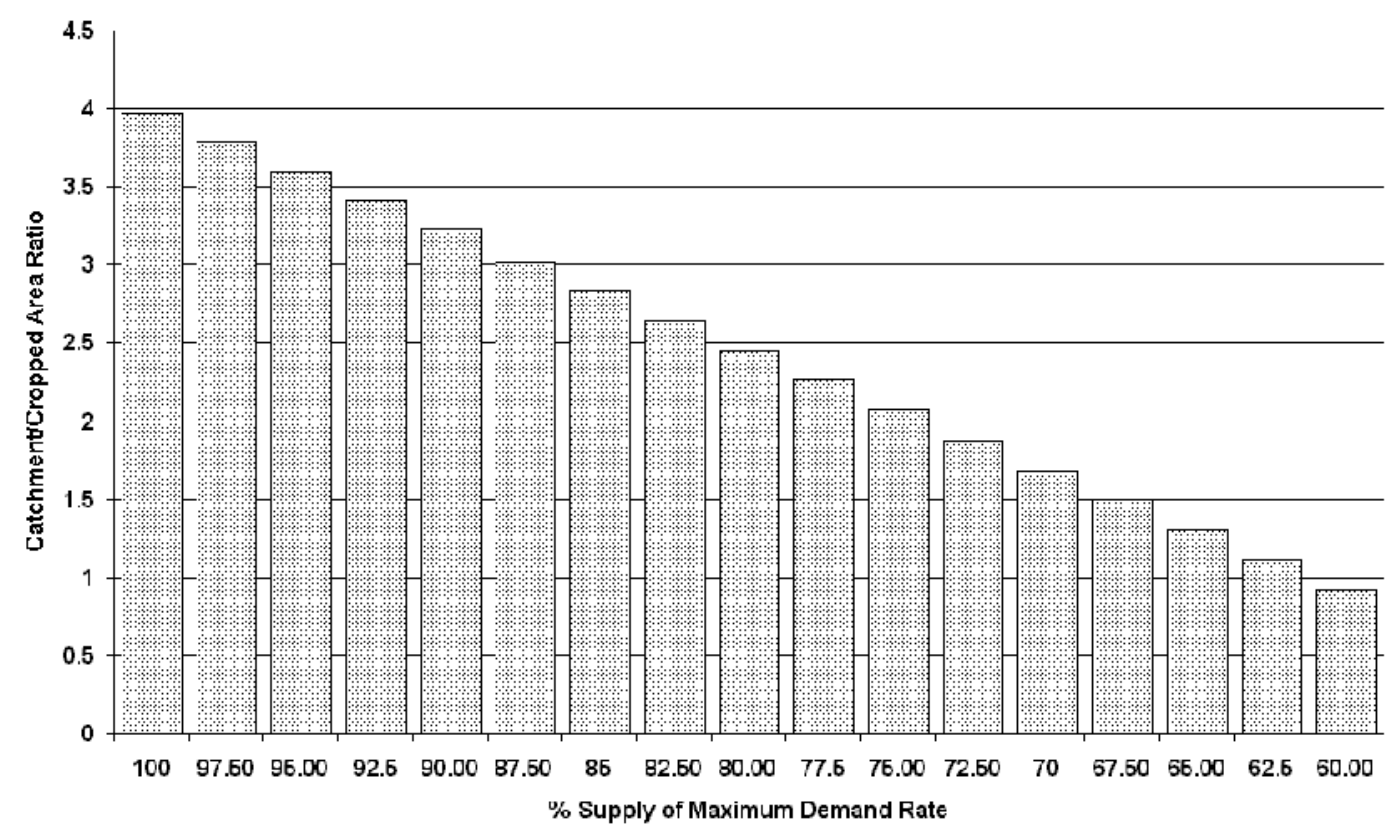

\section{Figure (4): Variation of catchment area to planting area ratio versus percentage of supply of maximum demand rate.}

For the analysis of the reservoir water balance using five-day intervals, Figure (5) shows the water stored in the reservoir, probable runoff volume, required supplemental irrigation volume (water pumped from reservoir), and evaporation loss for a 10 ha total land area. The results show that the maximum harvested runoff volume is about 825 $\mathrm{m}^{3} / 10$ ha, and the maximum stored runoff volume during the growing season is $1110 \mathrm{~m}^{3} / 10$ ha of land, which represents the required reservoir volume.

The results also showed that if the reservoir is designed at a lower probability level of assured rainfall and runoff, it will have a larger capacity and lower chance of being filled up to its full capacity. On the other hand, a reservoir designed on a higher probability level of assured rainfall will have a lower storage capacity but chances of being filled to full capacity will be greater and thus the expected cost of reservoir will be higher.

\section{Conclusion}

A simulation model for determining the optimum reservoir size for supplemental irrigation under rainfed farming conditions based on linear programming technique is presented. The volume of water stored in the reservoir depends on the available runoff water and the water demand for each interval during the growing season. 
The most important factors that govern the required harvesting (catchment) area and reservoir size are the unit cost of catchment area and unit construction cost of the reservoir. By implementing the proposed model, on an average rainfall year using the current market prices, and average year rainfall, the results showed that the required harvesting area is about $75 \%$ of the total area of land, and the required reservoir volume is about $1110 \mathrm{~m}^{3}$ per 10 ha of the total field area $\left(111 \mathrm{~m}^{3} / \mathrm{ha}\right)$. These optimal values occur at a $87.5 \%$ fulfillment of the maximum demand rate.

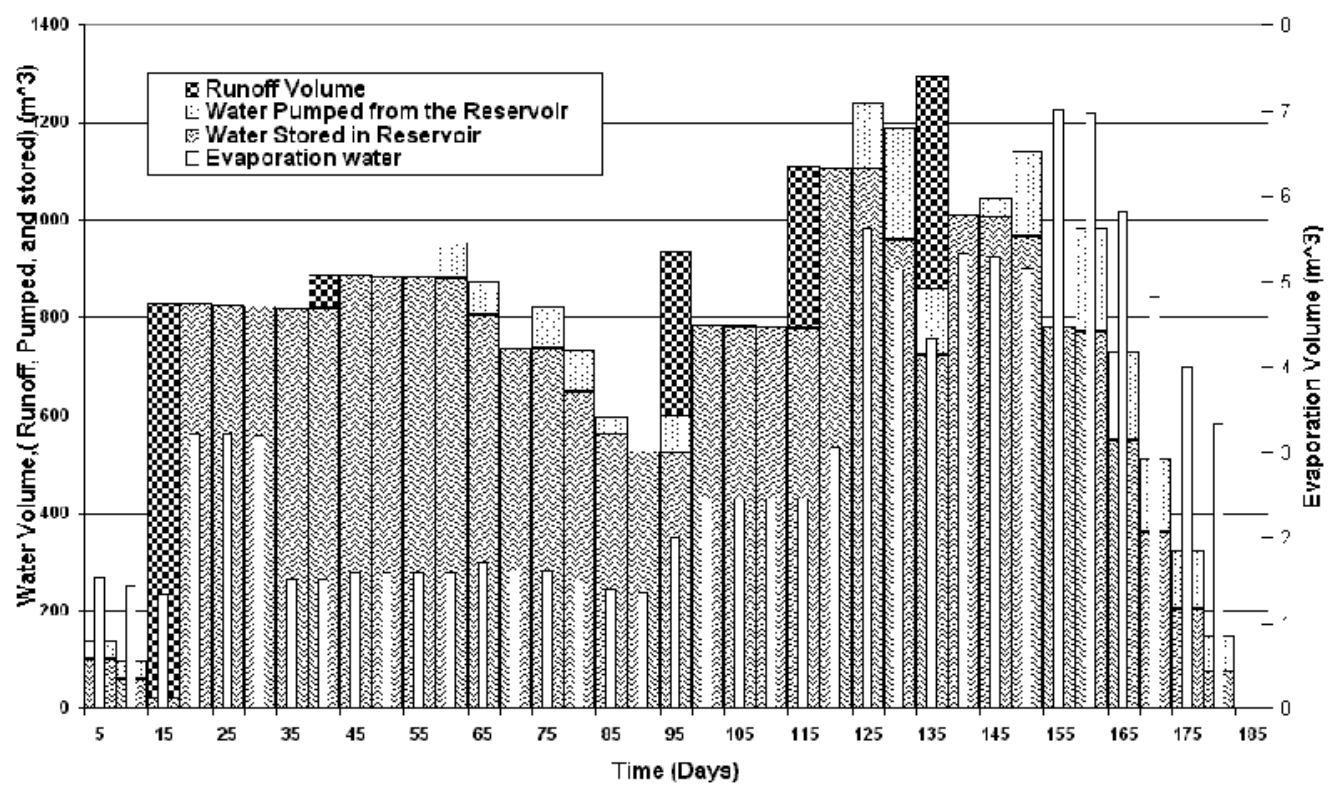

Figure (5): Stored water in the reservoir, runoff volume, required supplemental irrigation volume and evaporation volume for each 5-day time interval.

\section{References}

1- Oweis, T., Hachum, A., and Bruggeman, A., (eds). Indigenous Water Harvesting Systems in West Asia and North Africa. ICARDA, Aleppo, Syria. 2004, 173 pp

2- Palmer, W. L., Barfield, B. J., and Haan, C. T., Sizing farm Reservoir for Supplemental Irrigation of Corn; Part I: Modeling Reservoir Size Yield Relationship. Transaction of ASAE, vol. 25, No.2, 1982a , p.372-376.

3- Palmer, W. L., Barfield, B. J., and Haan, C. T., Sizing Farm Reservoirs for Supplemental Irrigation of Corn. Part II: Economic Analysis. Transaction of the ASAE, vol.25, No.2, 1982b, p.337- 
379.

4- Palmer, W. L., Barfield, B. J., and Haan, C. T., Sizing Farm Reservoirs for Supplemental Irrigation of Corn. Part II: Economic Analysis. Transaction of the ASAE, vol.25, No.2, 1982b, p.337-379.

5- Cundy, T. W., and Hawkins, R. H., Continuous distributed Model of Storage Dominated Watershed Runoff. Journal of Irr. and drain. Engg., vol. 115, No.2, 1989, p. 305-311.

6- Verma, H. N., and Sarma, P. B., Design of Storage Tanks for Water Harvesting in Rained Area. Journal of Agricultural Water Management, Vol.18, 1990, p.195-207.

7- Akan, A. O., Single - Outlet detention- pound analysis and design. Journal of Irr. and Drain. Engg., ASCE, vol.116, No.4, 1990, p.527536.

8- Cohen, I. S., Lopes, V. L., Slack, D. C., and Fogel, M. M., Water Balance Model for Small-Scale Water Harvesting Systems. Journal of Irr. And Drain. Engg., ASCE, vol.123, No.2, 1997, p.123-128.

9- Oweis,T., and Taimeh, A., Farm Water Harvesting Reservoirs: Issues of Planning and Management in Dry Areas, UNU-CAS International Workshop on Integrated Land Management in Dry Areas Beijing, China, 8-13 September 2001.

10- Pandey P. K., Panda, S. N. and Panigrahi, B., Sizing On-farm Reservoirs for Crop-fish Integration in Rainfed Farming Systems in Eastern India, Journal of Biosystems Engineering, Vol (93), No.4, 2006, p. 475-489.

11- Chow, V. T., Maidment, D. R. and May, L.W., Applied Hydrology. Mc Graw Hill International Book Company, new York, 1988, 572pp. 